Int. J. Electrochem. Sci., 16 (2021) Article ID: 210416

\title{
Influence of Magnetic Agitation and Bubble Stirring on Electrodeposited Copper in an Acidic $\mathrm{CuSO}_{4}$ Solution
}

\author{
Changlu Shan ${ }^{1,2}$, Qiushi Song ${ }^{1,2, *}$, Hongwei Xie ${ }^{1,2, *}$, Zhiqiang Ning ${ }^{1,2}$ \\ ${ }^{1}$ School of Metallurgy, Northeastern University, Shenyang 110819, China \\ ${ }^{2}$ Liaoning Key Laboratory for Metallurgical Sensor and Technology, Northeastern University, \\ Shenyang 110819, China \\ *E-mail: songqs@smm.neu.edu.cn, xiehw@smm.neu.edu.cn
}

doi: $10.20964 / 2021.04 .53$

Received: 16 December 2020 / Accepted: 27 January 2021 / Published: 28 February 2021

Electrochemical reduction is an effective method to transform $\mathrm{Cu}^{2+}$ ions into metallic $\mathrm{Cu}$ in aqueous solutions. Herein, magnetic agitation and flowing bubbles were introduced into the electrowinning process of $\mathrm{Cu}^{2+}$ ions in a $\mathrm{CuSO}_{4}-\mathrm{H}_{2} \mathrm{SO}_{4}$ electrolyte. The influence of agitation and micron-sized bubbles on the nucleation and growth of $\mathrm{Cu}$ electrodeposits was systemically investigated. Additionally, the composition and microstructure of the $\mathrm{Cu}$ deposits were analyzed. The migration of $\mathrm{Cu}^{2+}$ ions towards the cathode was effectively accelerated by agitation and bubbles. $\mathrm{Cu}$ dendrites can be basically eliminated in the product. Primary nucleation and the subsequent growth of the $\mathrm{Cu}$ electrodeposits were effectively promoted, while secondary nucleation of $\mathrm{Cu}$ was suppressed. Finally, compact and homogeneous $\mathrm{Cu}$ electrodeposits were prepared by employing agitation and flowing bubbles to assist the electrowinning of $\mathrm{Cu}$ ions.

Keywords: Electrowinning; copper; magnetic agitation; flowing bubble; kinetics

\section{$\underline{\text { FULL TEXT }}$}

(C) 2021 The Authors. Published by ESG (www.electrochemsci.org). This article is an open access article distributed under the terms and conditions of the Creative Commons Attribution license (http://creativecommons.org/licenses/by/4.0/). 